\title{
Refletindo Sobre o Futuro da Aprendizagem Através da Abordagem do Design
}

Reflecting on the Future of Learning through the Design Approach

BOECHAT, Cid; Mestrando em Design; PUC-Rio

cidboechat@gmail.com

MONT'ALVÃO, Claudia; Professor Associado; PUC-Rio

cmontalvao@puc-rio.br

\section{Resumo}

Reflete-se, aqui, sobre as perspectivas e tendências futuras da Educação, impulsionadas por diversas inovações tecnológicas. Através de grandes mudanças previstas para o campo educacional, são prometidos vários benefícios para os seres humanos. Porém, este artigo se pergunta: quais podem ser os malefícios dessas mudanças, especialmente no âmbito brasileiro? Se o Design projeta colocando o usuário no centro do processo, quais deverão ser os cuidados e responsabilidades dos designers ao construir as experiências educacionais futuras?

Palavras Chave: Futuro da Educação, Metodologias Colaborativas do Design, TICs

\section{Abstract}

This paper reflects on the perspectives and future trends of Education, driven by several technological innovations. Through major changes planned for this field, several benefits are promised to humans. However, what can be the bad side effects of these changes, especially in the Brazilian context? If a Design project places the user at the center of the process, what should be the designers' responsibilities in building future educational experiences?

Keywords: Future of Education, Collaborative Design Methodologies, ICTS 


\section{Introdução}

Desde o ensino presencial até as mais recentes abordagens ubíquas de aprendizagem, a Educação evolui no ritmo das mudanças tecnológicas e sociais. Com o surgimento de inovações como a Internet das Coisas, a Inteligência Artificial, a Big Data e a Realidade Virtual, prevê-se, em poucos anos, uma série de mudanças paradigmáticas na forma como se ensina: um novo papel do professor; a fusão entre as modalidades presencial e a distância; e a reconstrução das grades curriculares. As novas tecnologias e a chamada Quarta Revolução Industrial, que se avizinha, poderão afetar os arranjos organizacionais, o mercado de trabalho e as disciplinas abordadas e ofertadas nas instituições de ensino.

Como veremos ao longo deste artigo, estudiosos apontam uma série de vantagens nesta evolução educacional: acesso universal e popularizado ao conteúdo, conveniência, flexibilidade, autonomia e imersão. Mas há os que enxergam na oferta ininterrupta, universal e pervasiva de conteúdo a possibilidade de uma experiência opressiva para os alunos. Além disso, muitas dessas tecnologias exigem investimento em material didático e equipamentos específicos. Ao considerarmos a realidade brasileira, com vários problemas estruturais no ensino público, essas inovações serão uma chance de diminuir ou de aumentar (ainda mais) a distância entre o desempenho das escolas gratuitas e particulares?

Autores como Buchanan (2015) defendem que o Design é uma abordagem humanista, cujos projetos devem priorizar as pessoas direta e indiretamente envolvidas e por eles atingidas. Assim, o objetivo deste artigo é refletir sobre o papel dos designers na construção dessas novas experiências educativas. O que eles precisarão considerar e quais serão suas responsabilidades ao abordarem os futuros processos de ensino e aprendizagem?

Tendo em vista este cenário, o artigo contextualizará a relação entre Educação e as Tecnologias de Informação e Comunicação (TICS). Antes uma prerrogativa mais próxima da Educação a Distância (EAD), o uso de diferentes mídias e ferramentas vem se expandindo para as salas de aula e esmaecendo as fronteiras entre ensino remoto e presencial. Em seguida, será abordado como, ao longo dos anos, as formas de educar foram modificadas pelas tendências sociais e tecnológicas. Será mostrado como o ensino presencial e a distância evoluíram para o elearning, o ensino mobile e a Educação Ubíqua, num processo que se acentua e se acelera. Serão apontadas, ainda, as características e demandas desses processos educacionais na hora de projetar experiências. $O$ artigo também apresentará algumas previsões e correntes de estudo sobre as mudanças na Educação para os próximos anos: como serão as escolas? 0 papel dos professores será modificado? As formas de avaliação serão as mesmas?

Como reflexão final, o artigo abordará a visão do humanista do Design e questionará: ao se projetar a Educação do futuro, como colocar o ser humano no centro do processo? Quais os perigos que alunos, professores e demais envolvidos podem correr? Como fazer com que eles tenham a melhor experiência possível? Quais as responsabilidades dos designers nessa abordagem e como eles podem atuar nesse campo?

\section{A tecnologia e as mudanças na Educação}

Ao se falar da relação entre as Tecnologias de Informação e Comunicação e o campo educacional, é preciso considerar o cenário social como um todo. Vivencia-se, no século XXI, uma 
revolução tecnológica que mudou o mundo. A popularização da internet e da telefonia móvel, além das tecnologias de streaming, armazenamento de arquivos e o aumento da capacidade de processamento de dados, mudaram radicalmente a vida e a comunicação. A primeira década do século trouxe inovações como Moodle, Skype, redes sociais (Orkut, Facebook), tablets, smartphones, livros digitais (como o Kindle), streaming gratuito de vídeo (Youtube) e a banda larga móvel (3G e 4G), que impactaram fortemente a Educação. Oliveira, Moura e Souza (2015) sublinham que as novidades da informática tornaram cada vez mais presente o uso de ferramentas tecnológicas no processo de ensino. As inovações modificaram as atividades educacionais, através de projetos calcados em tecnologia e aprendizagem. Ainda segundo os autores, o uso do computador e da Internet trouxeram para os estudantes uma "avalanche de informações que as escolas e os professores, muitas vezes, não estão preparados para absorver". Assim, os paradigmas da Educação, em geral, foram modificados. Andrade e Lopes (2012), citando a visão de Litto (2009), afirmam que a internet permitiu que os limites entre disciplinas, instituições e locais geográficos se tornassem cada vez menos perceptivos. Formiga (2009) considera que essa mudança de paradigma levou o processo educativo a se tornar uma aprendizagem mais flexível, com conveniência de local e hora e conteúdos variáveis. O processo tornou-se coletivo, e nele o professor - que passa a ser um orientador de aprendizagem - deixa de apenas ensinar, para também aprender a aprender.

Quadro 1 - As fases da Educação, relacionadas com inovações tecnológicas e tendências sociais

\begin{tabular}{|c|c|c|}
\hline Momento Educacional & Tecnologia & Tendências \\
\hline Educação face-a-face & $\begin{array}{l}\text { Livros, lápis, caneta, quadro } \\
\text { negro }\end{array}$ & Escola Tradicional. \\
\hline EAD & $\begin{array}{l}\text { Livros impressos, } \\
\text { correspondência, rádio, telefone }\end{array}$ & $\begin{array}{l}\text { Estudo em casa, baixa } \\
\text { interatividade, liberdade de hora } \\
\text { e local, Open University. }\end{array}$ \\
\hline $\begin{array}{l}\text { T-Learning (conteúdo passado através } \\
\text { de transmissão) }\end{array}$ & $\begin{array}{l}\text { Televisão, vídeo, transmissão ao } \\
\text { vivo }\end{array}$ & $\begin{array}{l}\text { Estudo independente, } \\
\text { conferências por vídeo, } \\
\text { interatividade. }\end{array}$ \\
\hline E-Learning & $\begin{array}{l}\text { Computador, internet, sites, } \\
\text { portais, livros eletrônicos, blogs, } \\
\text { Wiki }\end{array}$ & $\begin{array}{l}\text { Alta interatividade, web } \\
\text { conferência, Redes Sociais }\end{array}$ \\
\hline M-Learning (ensino móvel) & $\begin{array}{l}\text { Celulares, tablets, computadores } \\
\text { portáteis. Leitores de e-books }\end{array}$ & $\begin{array}{l}\text { Portabilidade, ensino informal, } \\
\text { espontaneidade, }\end{array}$ \\
\hline T-Learning II (baseado em IP) & IPTV, Web TV, Web 3.0 & $\begin{array}{l}\text { Ambiente pessoal de } \\
\text { aprendizagem }\end{array}$ \\
\hline U-learning (aprendizagem ubíqua) & $\begin{array}{l}\text { Semântica, realidade } \\
\text { aumentada, nanotecnologia }\end{array}$ & $\begin{array}{l}\text { Imersão, integração com } \\
\text { atividades cotidianas, } \\
\text { Inteligência Artificial }\end{array}$ \\
\hline
\end{tabular}

Fonte: baseado em LIMA (2016) 
Lima (2016), analisando o trabalho de Demiray (2011), relacionou a evolução dos processos educativos com as mudanças tecnológicas e as tendências sociais (Quadro 1). Essa relação é, na verdade, uma linha do tempo que pode funcionar como um "mapa" para guiar a análise da ligação entre tecnologia, educação e as mudanças de paradigma. Ainda segundo Lima (2016), a EAD, por ser mais intrinsicamente ligada ao uso de mídias, foi a primeira a ser impactada pelas inovações. Behar (2009) define a Educação a Distância como uma aprendizagem organizada, em que há separação física entre professores e alunos, e a interação entre eles se realiza através de alguma tecnologia de midiatização. Desta forma, enquanto o ensino presencial se baseava prioritariamente na atuação do professor e nos livros didáticos, a EAD já se utilizava de mídias, como vídeos e transmissões de áudio, para vencer a distância entre docentes e alunos.

Assim, a Educação a Distância tradicional foi, aos poucos, dando lugar ao chamado elearning - a EAD após a internet. Teixeira e Weschenfelder (2013) afirmam que se pode falar de uma EAD antes e outra depois da internet e das tecnologias ligadas a ela:

Antes da internet tinha-se uma EAD que utilizava apenas tecnologias de comunicação de "um-para-muitos" (rádio, TV) ou de "um-para-um" (ensino por correspondência). Via internet há as três possibilidades de comunicação reunidas numa só mídia: "um-paramuitos", "um-para-um" e, sobretudo, "muitos-para-muitos" (TEIXEIRA; WESCHENFELDER, 2013, p.7 e 8).

O e-learning é calcado na flexibilidade e na abertura do sistema, além da disponibilidade de recursos pedagógico-didáticos distribuídos por vários locais (LIMA, 2016; KHAN, 2000). Ele permite não só a interação bilateral entre formadores e formandos, assim como a comunicação direta entre os alunos, diminuindo o isolamento em relação aos seus pares (TRINDADE, 2004). Moran (2010) reafirma esta questão, ao lembrar que as tecnologias da chamada Web 2.0 (blogs, podcasts, wikis), aliadas aos sistemas de gestão e aos Ambientes Virtuais de Aprendizagem (AVAs), permitem aos alunos protagonizar o processo de aprendizagem e a comunicação horizontal com seus pares e redes de interesse. Em geral, as instituições disponibilizam o e-learning num modelo próximo ao da Open University da Inglaterra, tendo o material textual como a base e oferecendo ambientes virtuais onde o aluno acessa atividades, material complementar, comunidade estudantil e tutoria. Também pode se oferecer tutoria presencial em polos ou por videoconferência.

A velocidade do desenvolvimento tecnológico e sua rápida popularização e adoção não permitiriam que essas ferramentas ficassem restritas à EAD. Litto (2009) lembra que, no passado, as instituições de ensino determinavam as tecnologias com as quais os alunos aprenderiam. Hoje, elas buscam se adaptar às tecnologias que os alunos já possuem. Assim, cada vez mais os objetos midiáticos são incorporados ao ensino presencial. Se antes se pôde afirmar que a EAD utilizava melhor ferramentas como rádio, TV, computadores e a Internet, o ensino presencial vem perdendo seu "conservadorismo" e passando a adotar novas ferramentas e práticas, o que faz essas duas modalidades convergirem (ANDRADE; PEREIRA, 2012).

(...) as experiências com as TCls na EaD estão estimulando mudanças nas práticas pedagógicas da educação presencial. Dito de uma outra maneira e nas palavras de Tori (2010, p.28): “Aos poucos, os recursos e as técnicas destinados inicialmente à educação eletrônica virtual foram sendo descobertos e aplicados pela educação convencional (ANDRADE; PEREIRA, 2012, p.2).

Essa necessidade de convergência é explicada por Moran (2010), ao dizer que não se 
consegue mais preparar as pessoas para o complexo mundo atual sem inserir tecnologias conectadas no processo educativo. Hoje, exige-se o domínio de linguagens e recursos digitais, e uma escola não conectada seria, na sua visão, incompleta. Segundo dados de 2015 da ABED (Associação Brasileira de Educação a Distância), o uso de conteúdos como áudios, vídeos, livros eletrônicos e objetos de aprendizagem digitais já é perceptível também no presencial (Figura 1). Outro uso que também se amplia é o de recursos conectados (AVAs, redes sociais e aplicativos de mensagens) para comunicação e compartilhamento de materiais (ABED, 2015). É importante lembrar que esses números podem ser amplificados pela legislação brasileira, que permite a um curso superior presencial ministrar até $20 \%$ do seu conteúdo à distância.

Figura 1 - Tipos de conteúdo utilizados em diferentes modalidades de ensino

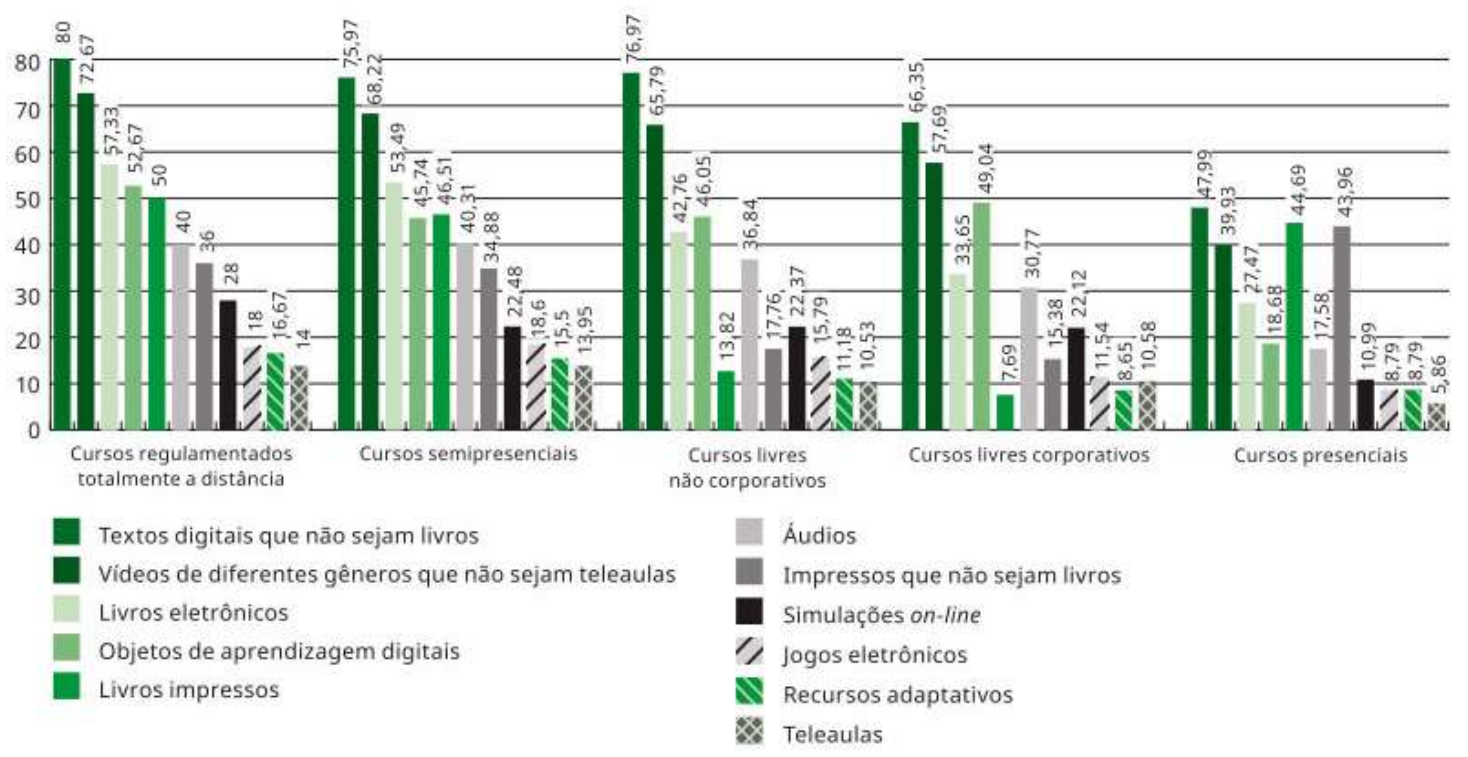

Fonte: ABED (2016)

A convergência entre presencial e EAD fica explicitada no chamado Ensino híbrido (também conhecido como Blended Learning ou B-Learning). Segundo Cardoso (2005), este é um processo de formação que combina as vantagens da experiência presencial com os recursos de TICs. As abordagens pedagógicas são diversificadas e escolhidas em função do contexto de ensinoaprendizagem encontrado. O B-Learning mistura o ensino presencial tradicional e o online, "flexível para a concepção de uma disciplina, que suporta uma mistura de diferentes tempos e locais de aprendizagem", onde o aluno recebe algumas das conveniências do online, mescladas com o presencial (CARDOSO, 2005; LIMA, 2016). Pode-se exemplificar esse tipo de ensino com a chamada Sala de Aula Invertida, onde o aluno estuda remotamente e pratica os conceitos estudados em sala.

Outro modelo educacional de muito potencial, especialmente na realidade brasileira, é o do Ensino móvel (também chamado de M-Learning ou Mobile Learning). Ele permite o acesso a conteúdos sem limites de espaço ou tempo, além de possibilitar a organização da aprendizagem de forma mais flexível (MOURA; CARVALHO, 2011). Em 2016, o Brasil tinha 38,3 milhões de pessoas acessando a internet através de celulares ou tablets, sendo que 8,7 milhões utilizavam 
apenas dispositivos móveis para se conectar (O GLOBO, 2016). Ao mesmo tempo, matéria publicada pelo Diário do Nordeste em 2016 informava que os brasileiros lideravam o uso de smartphones na América Latina e ocupavam o sexto lugar no ranking mundial. Desta forma, processos de ensino-aprendizagem calcados em plataformas móveis teriam grande chance de impacto num país como o nosso.

Quinn (2011) define que o Ensino Móvel é o conjunto de atividades que permitem aos usuários receber, criar e interagir com a informação através de dispositivos móveis. As principais vantagens do M-Learning seriam uma autonomia muito maior para o usuário, que adquire portabilidade e mobilidade globais e incompatíveis com o computador de mesa. Além disso, o mobile traz a possibilidade de conexão praticamente contínua com a internet, levando a uma computação pervasiva e onipresente no cotidiano do usuário. Porém, cabe dizer que a plataforma móvel, por si só, pode ser subutilizada se apenas replicar o material oferecido nos dispositivos "fixos". Um uso mais profundo dessas ferramentas passa por pensar conteúdos específicos, que funcionem melhor em aparelhos móveis. Mais do que simplesmente oferecer uma versão mobile do AVA, busca-se materiais e atividades que usem todas as possibilidades dos celulares, notebooks e tablets. Isso traria algumas questões, como as abordadas por Castillo e Ayala (2012): esses conteúdos precisam ser projetados levando em conta a forma como serão utilizados e distribuídos nos ambientes móveis. Também é preciso conceber e implementar atividades que sustentem as práticas de inovação educacional. No âmbito da EAD brasileira, o uso da tecnologia mobile na educação ainda é tímido. Segundo o Censo da ABED de 2014, de 254 instituições pesquisadas, $174(68,5 \%)$ ainda não haviam incorporado dispositivos móveis nos cursos de EAD que ofereciam (ABED, 2015).

Por fim, segundo Lima (2016), o momento mais recente da linha do tempo da Educação seria o da Aprendizagem Ubíqua. Também chamada de U-learning, ela resulta do uso cada vez mais pervasivo de computadores, no sentido mais lato, como parte integral do dia-a-dia. É um produto da web semântica (ou Web 3.0), das tecnologias que começam a permitir aos computadores atribuir sentido aos conteúdos. É um fruto da inteligência artificial, da realidade aumentada e da nanotecnologia. A Aprendizagem Ubíqua permitirá integração completa com as atividades diárias e imersão nas atividades pedagógico-didáticas. Ambientes virtuais e espaços físicos serão combinados, de forma que momentos individuais de aprendizagem poderão ser inseridos na vida cotidiana. As limitações espaço-temporais diminuem e, assim, generaliza-se a experiência educacional, que passa a ser permanente (LIMA, 2016).

Ainda segundo Lima (2016), a Aprendizagem Ubíqua tem como pontos fortes a capacidade de customização, personalização e adaptação. Poderiam ser criados, por exemplo, ambientes de aprendizagem baseados na localização do usuário, modificáveis de acordo com o contexto ao redor do estudante. O U-learning é possível graças ao aumento de dispositivos móveis na sociedade e à disponibilidade das redes públicas de telecomunicações. O futuro, provavelmente, terá alunos mais autodirigidos e motivados, centrados em ambientes de aprendizagem pervasivos e facilitados por instrutores e especialistas online.

Para abordar o papel e responsabilidades dos designers no projeto dessas experiências educacionais, é preciso observar o que está se prevendo para o futuro da educação nos próximos anos. A tecnologia conectada e ubíqua terá um grande impacto não só nas formas de aprendizagem, mas também nas ferramentas de avaliação, no papel dos alunos na construção dos currículos e no próprio cerne do processo de ensino-aprendizagem, num mundo que está 
mudando rápido. A seguir, o artigo apresentará algumas das especulações sobre esses temas.

\section{Tendências para o futuro da Educação}

Apontar o caminho no qual seguirá a educação - e a sociedade como um todo - para os anos de 2025, 2030 e além é, neste ponto, um exercício de "futurologia". Muitos estudiosos e profissionais do mercado olham para tendências sociais e tecnológicas, mas talvez seja difícil, e pouco científico, fazer afirmações efetivas. Ainda assim, alguns grupos e pesquisas projetam o status do ensino-aprendizagem nos próximos anos. Em 2014, por exemplo, o Pew Research Group, em conjunto com a Universidade de Elon (EUA), lançou um relatório chamado Digital Life in 2025. Nele, centenas de especialistas opinaram sobre a influência da Web em vários aspectos da sociedade na década de 2020. Muitos dos especialistas eram acadêmicos das principais instituições públicas e privadas de ensino superior dos Estados Unidos e de outros países. Também foi colhida a opinião de "leigos", para se obter a visão de pessoas "comuns" sobre a abundância de informações digitais e a conectividade constante (MORRISON, 2014). No que tange a Educação, espera-se que a evolução das ferramentas online expanda as formas de transmissão e as oportunidades da educação formal. Também se prevê menos gastos com estrutura física e professores. Alguns especialistas veem que a aprendizagem se tornará independente da qualidade dos pais e dos professores, já que os alunos terão acesso global aos melhores conteúdos e materiais. Também se vê uma mudança de paradigma no modelo institucional das organizações de ensino atuais, especialmente no ensino superior. Os professores "locais", presenciais, passariam a ser tutores, enquanto os verdadeiros "mestres" ensinariam remotamente (MORRISON, 2014; ANDERSON; RAINIE, 2014).

Henny (2016), no sítio eletrônico elearningindustry.com, fez algumas previsões sobre como seria a educação em 20 anos. Entre elas: a adoção da aprendizagem personalizada (com ferramentas adaptáveis); a liberdade de escolha (os alunos poderão modificar seu processo de aprendizagem); projetos como base do ensino (a futura economia freelance exigiria carreiras e aprendizagem baseados em projetos); o uso de muitas atividades de campo (com maior espaço para habilidades de conhecimento humano); a interpretação de dados (que se tornaria mais importante que a matemática "tradicional"); mudanças nos processos de avaliação (com o conhecimento factual medido durante a aprendizagem, conhecimentos seriam testados em projetos no campo); a "coautoria" do estudante (alunos seriam envolvidos na formação dos currículos, para que o conjunto de disciplinas se mantivesse contemporâneo, atualizado e útil); professores se tornariam mentores/tutores (o processo de aprendizagem seria tão independente que a orientação seria fundamental para o sucesso dos alunos). Os professores formariam um ponto central na selva de informações disponíveis para os alunos (HENNY, 2016).

Peter Diamandis, em 2015, publicou oito previsões sobre o impacto da tecnologia para os próximos 10 anos. Entre elas, que teríamos acesso ao "conhecimento perfeito", onde bilhões de sensores, espalhados por todos os lugares (carros, satélites, drones, wearables, câmeras), possibilitariam saber absolutamente qualquer coisa, a qualquer hora, em qualquer lugar. $\mathrm{A}$ conexão à internet seria praticamente global, com velocidade superior a 1 Gigabyte por segundo. A realidade aumentada e a inteligência artificial trariam uma ruptura em vários segmentos, como varejo, mercado imobiliário, educação, viagens e entretenimento (DIAMANDIS, 2015).

Em 2017, a empresa Nous Sense-Making realizou um estudo sobre dez tendências 
estratégicas para o Ensino Superior Brasileiro em 2025. Esse material foi construído através da identificação de visões de futuro, com base em processos de elaboração de cenários. Entre as previsões, a de uma Educação virtualizada, com uso cada vez maior de tecnologias e metodologias de EAD, e-learning e ensinos do tipo mobile e híbrido. Também se espera uma educação individualizada, pensada para e pelo aluno, com base na aprendizagem adaptativa. Outra tendência apontada é a utilização de modelos de formação e certificação de baixo custo e alta qualidade através de ferramentas como os MOOCs (cursos massivos online). Isso, além da oferta de conteúdos gratuitos, seria disponibilizado como complemento aos modelos formais de ensino. A empresa entende, ainda, que se usarão cada vez mais características das redes sociais na relação com os discentes, trazendo, assim, novas formas de comunicação e alterando o "engajamento, comunicação, integração e interação dos e com os alunos" (NOUS SENSE-MAKING, 2017). Assim como Henny (2016), a Nous Sense-Making também prevê uma formação baseada em projetos, calcada na análise de problemas, com apoio de novas metodologias como a sala de aula invertida. Outros dois pontos em comum entre eles são: a de que o papel do professor será muito mais próximo a de um tutor que facilita o direcionamento dos estudos aplicados; e de que o conteúdo focará nas novas demandas profissionais e no rápido movimento de fim e surgimento de carreiras, dando ênfase à resolução de problemas, empreendedorismo e experimentação digital. Analisando o relatório da Nous, Teixeira e Lopes (2017), do sítio eletrônico Radar do Futuro, enxergam para o Brasil uma educação que será obrigada a se moldar à capacidade de processamento, velocidade de tráfego de informações e poder de armazenamento da computação. A internet ultra veloz propiciará uma força adicional à inteligência artificial adotada nos processos de e-learning. 0 sistema irá entender a "linguagem natural através da qual os seres humanos se comunicam". Segundo os autores, máquinas que aprendem e processam a fala e que reconhecem imagens já são tecnologias quase prontas. Para eles, em 2025 será possível acompanhar a aula de um professor japonês e conversar com colegas chineses, em tempo real, através de tradução simultânea (TEIXEIRA; LOPES, 2017).

As experiências imersivas possíveis em 2025 deixarão espaço para o modelo atual, do aluno que se desloca até uma sala para ouvir um professor? Teixeira e Lopes (2017) acham difícil. O fortalecimento dos processos de EAD no ensino em geral, para eles, é inevitável, graças à capacidade de processamento e à internet em todos os lugares. Além disso, os alunos terão a oferta dos sistemas de Realidade Virtual (RV), Realidade Aumentada (RA) e Realidade Mista (RM), mesmo em sala de aula.

Desta forma, temos um panorama de algumas visões sobre o futuro dos processos de ensino. Enquanto projetistas desses sistemas e interações, cabem aos designers alguns questionamentos: a aprendizagem ainda será uma experiência entre humanos? A interação com ambientes e assistentes virtuais deixará o contato de alunos com professores e colegas em segundo plano? Até que ponto a adoção de determinadas metodologias e ferramentas são uma decisão educacional e não mercadológica? O professor se tornará obsoleto e poderá, um dia, ser totalmente substituído por máquinas? Ao se considerar cada uma dessas previsões para o futuro da aprendizagem, está se medindo quais as perdas e ganhos de cada opção? Esse serão alguns pontos abordados a seguir, de acordo com a visão de projeto calcada no Design. 


\section{0 projeto de futuras experiências educacionais sob a visão do Design}

A presença pervasiva de computadores e da internet de alta velocidade, aliada a tecnologias como a Inteligência Artificial, podem criar uma educação ultrapersonalizada e global. As vantagens desse cenário seriam uma capacidade de oferecer aprendizagem em tempo integral, em qualquer lugar e feita sob medida. Além disso, o nível de conhecimento absorvido pelo aluno conseguiria ser efetivamente medido. Mas, e os problemas? Quais as responsabilidades de quem projetará essa experiência? Como medir o que o aluno ganhará e perderá, comparado com o que se tem hoje?

Ao pensar e projetar essas futuras atividades educacionais através da visão do Design, é preciso colocar os seres humanos envolvidos no centro do processo. Ainda hoje, o Design é visto popularmente como uma atividade artística e associada a símbolos gráficos, produtos industriais, espaços interiores e edifícios. Porém, Buchanan (2004) defende que o Design é na verdade uma atividade que busca criar soluções práticas e efetivas na melhora da vida humana em todos os seus aspectos:

O Design é humanista porque se concentra na experiência humana dos produtos. É intelectual porque exige o conhecimento direto ou indireto de todos os fatores que devem ser integrados em um produto bem-sucedido, seja o produto como uma comunicação, um artefato, um serviço ou uma atividade de gerenciamento ou um ambiente. O Design oferece busca e resolução de problemas na vida prática através da criação de produtos que tenham integridade intelectual e satisfação emocional e estética (BUCHANAN, 2004, p.54, traduzido pelo autor).

Mudanças significativas nos paradigmas sociais se avizinham. O Fórum Econômico Mundial de Daros, em 2016, teve como tema principal a Quarta Revolução Industrial e o seu impacto no emprego a nível global. Segundo matéria publicada em 2016 no sítio eletrônico da Agência Brasil, estudos preveem uma perda líquida global de mais de cinco milhões de empregos até 2021. Fatores como a Internet das Coisas, Big Data e a Inteligência Artificial trarão uma mudança radical nos modelos de negócios atuais. Segundo a matéria, esse cenário demanda dos governos uma estratégia de transição que garanta mão de obra competente e preparada, ou a questões do desemprego e da desigualdade se agravarão (AGÊNCIA BRASIL, 2016). Ao mesmo tempo, máquinas com capacidade de "aprender" utilizarão nossas interações com elas para identificar padrões em dados e assim realizar previsões ou decisões (ARK, 2015). O chamado Machine Learning pode trazer mudanças profundas nos sistemas de ensino-aprendizagem. Segundo Nelson (2017) as máquinas serão capazes de analisar cada estudante individualmente e apontar quais métodos e ferramentas de ensino funcionam melhor para cada um. Há programas em desenvolvimento que permitirão avaliar o desempenho futuro do aluno através das suas notas e trabalhos atuais. $\mathrm{O}$ autor também prevê inteligências artificiais capazes de organizar currículos e esquematizar conteúdos de aulas. Elas poderão, ainda, ajudar os professores a dar notas sem o "viés" humano e a mandar mensagens de feedback sobre provas e trabalhos, além de sugerirem metodologias e atividades baseadas no perfil do aluno.

Estes cenários trazem uma série de questões a quem vai projetar experiências educacionais futuras. Por um lado, vive-se um momento crucial onde será preciso modificar os conteúdos e os modelos educacionais. A tecnologia trará, em pouco tempo, demandas aparentemente inescapáveis e que deverão ser consideradas pelos projetistas, sob o risco de um grave problema social causado pelo desemprego. Porém, não se deve esquecer da preocupação 
com os aspectos pedagógicos e humanísticos desta revolução. As TICs são ferramentas com imensas possibilidades, mas que dependem e demandam uma abordagem pedagógica diferenciada. Búrigo et al. (2016) reforçam que as ações pedagógicas ocupam lugar central no processo de gestão da educação, especialmente quando utilizam ferramentas da EAD. É o processo pedagógico que deve motivar a definição dos meios e a produção dos materiais e do sistema de comunicação, integradas no objetivo de fomentar a aprendizagem dos alunos. Mas serão os aspectos pedagógicos que guiarão esse processo de adoção de ferramentas e tecnologias? Se inevitavelmente necessita-se de um novo modelo educacional, ajustado para o futuro da sociedade, o que ele pode reter de positivo do modelo atual? Apesar de autores como Nelson (2017) afirmarem que as máquinas darão assistência, mas jamais substituirão os professores, cabe o questionamento: um acadêmico, por mais conhecimento que tenha, pode concorrer com uma Inteligência Artificial alimentada com todos os artigos e revistas científicas do mundo? Essas perguntas trazem uma reflexão mais importante, ao colocar o usuário no centro do processo: este cenário será melhor para os alunos? Se não for, ele é evitável?

Alguns autores como Barros (2014) apontam problemas nessa forma global e ininterrupta de acesso à aprendizagem. Para eles, a conectividade traz consigo a pressão da responsabilização das pessoas por seus desempenhos. No cenário da formação constante, a exigência sobre os indivíduos é levada a outro nível. Assim, nunca se terá estudado o suficiente, nunca se estará suficientemente qualificado, jamais haverá um currículo adequadamente bom para a completa garantia de empregabilidade. O estudante se torna "eterno", e o que era uma possibilidade constante de aumentar seus conhecimentos em um mundo cada vez mais competitivo, se torna apenas uma obrigação. O local de aprendizagem passa a ser todos os lugares, delimitado "pela eterna agonística do indivíduo contra si mesmo" (BARROS, 2014).

Os recursos de mídia e as novas TICs são defendidas por permitirem uma aprendizagem mais lúdica e trazerem facilidades, como o estudo remoto. Martinianos (2016) lembra que será possível medir o aprendizado instantaneamente e mensurar o quanto a pessoa leu, o que reteve de informações e quanto de sua capacidade o cérebro está usando. Se cada passo educacional de uma pessoa é individualmente medido, registrado e analisado de uma forma muito mais minuciosa do que hoje, isso não pode se tornar uma experiência sufocante?

Além disso, é preciso levar em consideração questões cognitivas no uso extensivo de ferramentas educacionais. Pesquisadores como Oviatt (2013) vêm realizando pesquisas empíricas sobre o impacto da tecnologia sobre a carga cognitiva dos alunos. Segundo suas pesquisas, embora a tecnologia possa acelerar o processamento do sistema, muitas vezes o faz minando os padrões de pensamento autorreguladores, integrativos e flexíveis que são essenciais para a construção ativa de representações mentais corretas. As ferramentas digitais muito ou incorretamente automatizadas, que completem tarefas para os alunos, podem prejudicar o esforço mental e a auto estrutura necessária para a aprendizagem (OVIATT, 2013). Haverá tempo para um estudo prévio sobre o impacto cognitivo de todas essas novas ferramentas sobre os estudantes? Ou só serão possíveis quando já estiverem em uso? Esse tipo de dado é fundamental para se projetar experiências de ensino-aprendizagem focadas no ser humano.

Uma das previsões sobre o futuro educacional é a participação do aluno na construção do currículo e na distribuição do conteúdo. O uso de processos colaborativos que envolvam os usuários é um ponto fundamental das metodologias participativas do Design. Nelas, os atores envolvidos são a melhor fonte de informações e respostas sobre a questão abordada, já que 
vivenciam o objeto de estudo cotidianamente (SILVA, 2012). Porém, dada a complexidade da questão educacional, talvez o nível e o tipo de participação e avaliação dos usuários precisem ser mais profundos. O Design Participativo, por exemplo, busca e pensa métodos que ocorram em colaboração com os usuários. Silva (2012) afirma que um projeto de Design Participativo deve se apoiar na valorização do conhecimento tácito e subjetivo. Designers devem interagir com os atores envolvidos até que eles externalizem este conhecimento. Com as informações coletadas, forma-se a base para idealizar e avaliar possíveis soluções. Pressionados pelas demandas sociais do emprego e do mercado, é possível que os alunos demonstrem contentamento com algum modelo educacional, mesmo que esta não seja realmente sua opinião. Talvez, se precise ir além do que é apenas declarado. Silva (2012) faz referência ao trabalho de Sanders (2002), onde a empatia com o usuário é resultado da apreensão do que ele comunica nos níveis explícito, observável, tácito e latente (Figura 2). Para isso, é preciso perceber os desejos e necessidades expressados nesses diferentes níveis. Apenas a verbalização não é suficiente, pois mostraria somente o que o usuário quer ou consegue expressar. A observação do que o usuário faz - e de que forma - permite a percepção do seu conhecimento tácito e seus desejos latentes.

Figura 2 - Níveis de conhecimento e formas de expressá-los

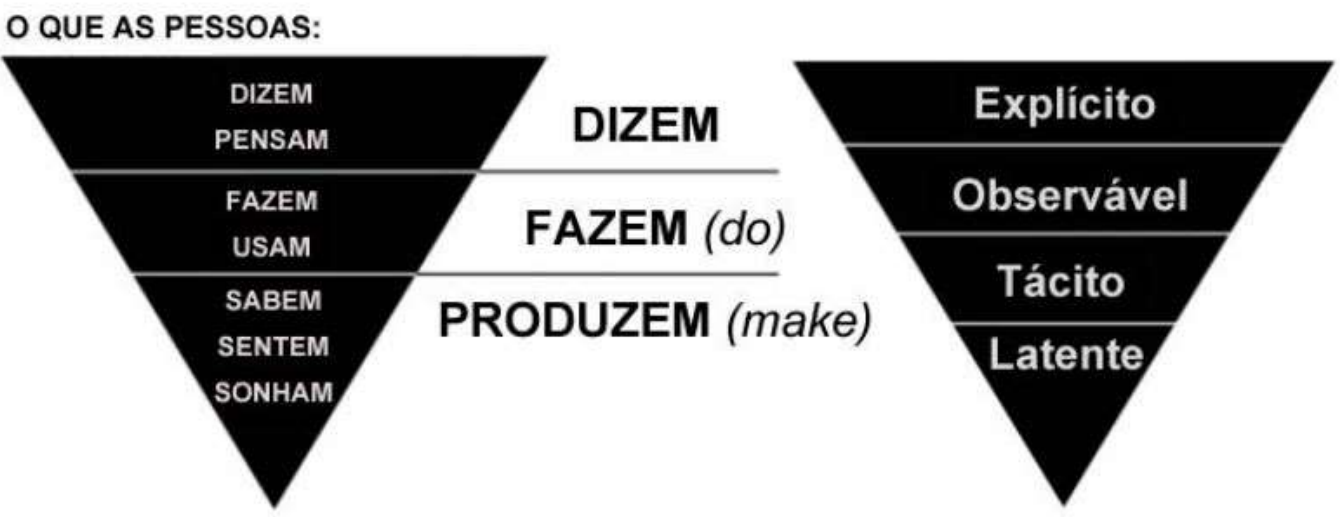

Fonte: SILVA (2012), baseado em SANDERS (2002) e traduzido pelo autor

Outra questão que se coloca, neste aspecto, é saber até que ponto estudantes muito jovens têm maturidade e vivência suficientes para definir seus currículos. Se não é incomum encontrar quem se arrependa do curso de graduação que escolheu aos dezessete anos, o que dizer de alunos ainda mais jovens? Um estudante de catorze anos tem conhecimento suficiente para opinar sobre a definição do seu currículo? Seria papel do professor, nessa nova função mais tutorial, ajudá-lo a tomar essas decisões? Além disso, nas esferas superiores da graduação, currículos calcados no utilitarismo mercadológico poderiam aproximar as universidades dos cursos técnicos, ao invés de espaços para reflexão. Qual será o papel da Academia em uma educação mediada, planejada e disponibilizada por máquinas?

Projetar com foco no ser humano também é jamais se esquecer do contexto onde os usuários estão inseridos, e esta é outra responsabilidade do designer. O cenário ao redor dos steakholders tem importância fundamental: as características, contingências e influência dos ambientes externos e internos devem ser cuidadosamente observadas e consideradas. Assim, é 
preciso colocar na perspectiva brasileira essa educação fortemente calcada no uso de tecnologias e na internet de alta velocidade. O Brasil possui vasto território e regiões de difícil acesso, que podem dificultar a implementação da uma internet global e de alta qualidade. Além disso, o país sofre com problemas de estrutura e desigualdade educacionais. Matéria publicada em 2015 pela revista Época aponta que, segundo dados da Prova Brasil, mais de 65\% dos alunos brasileiros no quinto ano da escola pública não sabiam reconhecer quadrados, triângulos e círculos. Os dados também apontavam uma grande desigualdade entre os estados brasileiros. Enquanto em São Paulo e Santa Catarina metade dos alunos tinha aprendizado adequado em Português, em Alagoas e no Maranhão esse número não chegava a 20\% (GUIMARÃES, 2015). Outra questão importante é a péssima estrutura de muitas escolas brasileiras. Matéria veiculada pelo Jornal Nacional em 2015 noticiou que a cada vinte escolas públicas de ensino fundamental no Brasil, só uma possuía a estrutura básica para educar. Não era incomum, segundo o levantamento, encontrar escolas sem bibliotecas, laboratórios, tratamento de esgoto e luz elétrica (JORNAL NACIONAL, 2015). Isto posto, cabe questionar se a aposta em experiências educacionais tecnológicas e conectadas não ampliará a desigualdade entre os estados ricos e pobres e entre os alunos das escolas públicas e privadas. Os governos terão a capacidade e a celeridade de investimento para suprir os alunos com os recursos e ferramentas necessários? Pensando no caso específico brasileiro, a revolução prometida por essa educação flexível e pervasiva seria para todos?

Segundo Buchanan (2015), um princípio intrínseco do Design é buscar não só a lucratividade, mas, também, a melhora significativa da vida das pessoas. Já Brown (2010), afirma que o que diferencia e orienta a forma de pensar do Design é o foco nas necessidades humanas fundamentais, e não em "desejos efêmeros ou artificialmente manipulados". A participação dos designers neste processo não poderá se dar apenas nas suas etapas finais, projetando interfaces e interações de ferramentas e devices. Será preciso pensar a experiência educacional como um todo, desde o início, buscando mais do que as demandas mercadológicas e centralizando o ser humano ao longo do processo. Convidar todos os atores impactados pelas mudanças a participar dessa construção, mas indo além do que é apenas declarado. Buscar os sentimentos de pais, docentes, alunos e demais envolvidos, sem se prender ao utilitarismo objetivo. Designers deverão considerar o contexto ao redor dessas pessoas e propor soluções colaborativas que envolvam, da melhor forma possível, todos os prismas da questão. É prometido que a mudança no paradigma educacional trará um novo aprendizado mais universal, livre, rico e prazeroso. Mas vimos que esta questão é muito mais complexa na prática. Se fazer Design é focar no ser humano, será responsabilidade do designer projetar uma experiência educacional que supra as necessidades da sociedade e do mercado, sem que isso se torne uma experiência ruim ou opressora.

\section{Conclusões e desdobramentos futuros}

As mudanças previstas para o processo educacional são uma questão crucial para a humanidade nos próximos anos. Este artigo procurou mostrar o cenário complexo no qual o processo de ensino-aprendizagem está inserido e suas perspectivas para o futuro. Buscou-se que os questionamentos aqui levantados fomentem uma reflexão sobre o papel do Design neste processo.

Para abordar e gerir esse novo paradigma educacional, Martinianos (2016) defende uma formação em Engenharia de Tecnologias Educativas, com conhecimento de tecnologias em 
Educação, gestão estratégica e estruturada de projetos, habilidade no trato com recursos humanos e compreensão dos processos cognitivos, como a Neuroeducação. Indo um pouco além, este artigo acredita que o Design, com sua visão humanística, deveria se envolver nesse planejamento multidisciplinar, contribuindo, com sua abordagem, para a construção de experiências de qualidade num campo tão fundamental.

Como desdobramento futuro, espera-se mais debates sobre esta questão no âmbito interno do Design. Também se espera uma participação maior de designers em pesquisas de áreas como Educação, Psicologia, Neurociência, Economia e Antropologia, entre outras. Nelas, que se busque uma matriz, uma guideline multidisciplinar onde sejam avaliadas as demandas do mercado, as questões pedagógicas e neuroeducativas e os desejos explícitos e latentes dos seres humanos envolvidos.

\section{Referências}

ABED - ASSOCIAÇÃO BRASILEIRA DE EDUCAÇÃO A DISTÂNCIA. Censo ead.br: relatório analítico da aprendizagem a distância no Brasil 2015. Curitiba: InterSaberes, 2016.

ABED - ASSOCIAÇÃO BRASILEIRA DE EDUCAÇÃO A DISTÂNCIA. Censo ead.br: relatório analítico da aprendizagem a distância no Brasil 2014. Curitiba: Ibpex, 2015.

AGÊNCIA BRASIL. Quarta revolução industrial é tema do Fórum Econômico Mundial em Davos. In: Agência Brasil, 2016. (http://agenciabrasil.ebc.com.br/internacional/noticia/2016-01/quartarevolucao-industrial-e-tema-do-forum-economico-mundial-em-davos)

ANDRADE, F. V.; LOPES, A. M. DE A. EaD: uma história de inovações tecnológicas no Brasil. Anais do Citi - 7. Congresso de Tecnologia da Informação, 2012.

ANDRADE, L.A.; PEREIRA, E. Educação a distância e ensino presencial: convergência de tecnologias e práticas educacionais. Anais do Simpósio Internacional de Educação a Distância e Encontro de Pesquisadores em Educação a Distância, 2012.

ANDERSON, J.; RAINIE, L. Digital Life in 2025.In: Pew Research Center, 2014. (http://www.pewinternet.org/2014/03/11/digital-life-in-2025/)

ARK, T. 8 Ways Machine Learning Will Improve Education. In: Getting Smart, 2015. (http://www.gettingsmart.com/2015/11/8-ways-machine-learning-will-improve-education/)

ARRUDA, E. P.; ARRUDA, D. E. P. Educação a Distância no Brasil: Políticas Públicas e democratização do acesso ao Ensino Superior. Belo Horizonte: Educação em Revista, v. 31, n. 3, p. 321-338, set. 2015.

BARROS, J. Democracia E Utopia Na Sociedade Do Conhecimento: Reflexões Sobre a Educação a Distância. 2014. 227 f. Tese (Doutorado) -USP, Curso de Pós-Graduação em Educação.

BEHAR, P. A. Modelos Pedagógicos em Educação a Distância. Porto Alegre: Artmed, 2008.

BONOMA, T. Case Research in Marketing: Opportunities, Problems, and Process. Chicago: Journal of Marketing Research, 1985.

BROWN, T. Design Thinking. Rio de Janeiro: Elsevier, 2010.

BUCHANAN, R. Management and Design: Interaction Pathways in Organizational Life. In: BOLAND 
JR., R. J.; COLLOPY, F. (Orgs.). Managing as Designing. Stanford: Stanford University Press, 2004. P. 54-64.

BUCHANAN, R. Worlds in the Making: Design, Management, and the Reform of Organizational Culture. Xangai: She Ji: The Journal of Design, Economics and Innovation, 2015.

BÚRIGO, C. C. D. et al. A Gestão Colaborativa no processo formativo da EAD. Revista Gestão Universitária na América Latina - GUAL, v. 9, n. 1, p. 165-176, 2016.

CARDOSO, L. Ambientes de Ensino Distribuído na Concepção e Desenvolvimento da Universidade Flexível. 2005. Tese (doutorado) - Universidade do Minho, curso de Pós-Graduação em Sistemas de Distribuição.

CASTILLO, S.; AYALA, G. Mobile Learning. In: SEEL, N. (Org.). Encyclopedia of the Sciences of Learning. Boston: Springer, 2012.

DIAMANDIS, P. The World in 2025: 8 Predictions for the Next 10 Years. In: Singularity Hub, 2015. (https://singularityhub.com/2015/05/11/the-world-in-2025-8-predictions-for-the-next-10years/\#sm.000uk7v6e8ahd6410pk1y69d5uaio)

FORMIGA, M. A terminologia da EAD. In: LITTO, F. M.; FORMIGA, M. (Org.). Educação a distância: o estado da arte - Volume 1. São Paulo: Pearson, 2009. p. 39-46.

GUIMARÃES. C. O ensino público no Brasil: ruim, desigual e estagnado. In: Revista Época, 2015. (http://epoca.globo.com/ideias/noticia/2015/01/bo-ensino-publico-no-brasilb-ruim-desigual-eestagnado.html)

HENNY, C. 9 Things That Will Shape The Future Of Education: What Learning Will Look Like In 20 Years? In: E-learning Industry, 2016. (https://elearningindustry.com/9-things-shape-future-ofeducation-learning-20-years)

JORNAL NACIONAL. Estudo revela falta de estrutura em escolas brasileiras. In: Jornal Nacional, 2015. (http://g1.globo.com/jornal-nacional/noticia/2015/09/estudo-revela-falta-de-estrutura-emescolas-brasileiras.html)

KHAN, B. H. A Framework for Web-Based Learning. TechTrends, v. 44, n. 3, 2000.

LIMA, R. G. Depois do e- e do b-, o m- e o u-(learning): uma breve incursão pelos paradigmas emergentes da educação à distância. Revista da FLUP, IV Série, v. 6, p. 141-157, 2016.

LITTO, F M. O atual cenário internacional da EAD. In: LITTO, F. M.; FORMIGA, M. (Org.). Educação a distância: o estado da arte - Volume 1. São Paulo: Pearson, 2009. p. 14-20.

MARTINIANOS, V. Hologramas serão os professores do futuro, prevê pesquisador: depoimento. [30 de maio, 2016]. Curitiba: Gazeta do Povo. Entrevista concedida a Adriana Czelusniak. (http://www.gazetadopovo.com.br/educacao/hologramas-serao-os-professores-do-futuro-prevepesquisador-0hm133vuckmd0c2df1xc7do21)

MORAN, J. A distância e o presencial cada vez mais próximos: depoimento. [25 de maio, 2010]. Rio de Janeiro: Folha Dirigida. Entrevista concedida a Paulo Chico.

MORRISON, D. What Will Education Look Like in 2025? What the Experts Have to Say. In: Online Learning Insights, 2014. (https://onlinelearninginsights.wordpress.com/2014/03/14/what-willeducation-look-like-in-2025-what-the-experts-have-to-say/) 
MOURA, A. Apropriação do Telemóvel como Ferramenta de Mediação em Mobile Learning: Estudos de Caso em Contexto Educativo. 2010. Tese (doutorado) - Universidade do Minho, curso de Pós-Graduação em Ciências da Educação.

MOURA, A.; CARVALHO, A. Aprendizagem mediada por tecnologias móveis: novos desafios para as práticas pedagógicas. Proceedings of the VII International Conference on Information and Communication Technologies in Education - Challenges 2011: Perspectives on Innovation.

NELSON, K. 8 ways machine learning will improve education. In: Big Data Made Simple, 2017. (http://bigdata-madesimple.com/8-ways-machine-learning-will-improve-education/)

NORDESTE, D. DO. Brasil é o 60 em uso de smartphones no mundo; na América Latina o País é o líder. In: Diário do Nordeste, 2016. (http://diariodonordeste.verdesmares.com.br/suplementos/tecno/online/brasil-e-o-6-em-uso-desmartphones-no-mundo-na-america-latina-o-pais-e-o-lider-1.1190571)

NOUS SENSE-MAKING. 10 tendências estratégicas que moldarão o ensino superior no Brasil em 2025. In: Sous Sense-Making, 2017. (https://drive.google.com/file/d/OByH31jlA_fcUOVpeWdTWml1NjQ/view)

OLIVEIRA, C.; MOURA, S.; SOUZA, E. TIC's na Educação: a utilização das tecnologias da informação e comunicação na aprendizagem do aluno. Pedagogia em Ação, [S.I.], v. 7, n. 1, 2015.

O GLOBO. Usuários de internet móvel no Brasil crescem $7 \%$ nos últimos seis meses e chegam a 38,3 milhões. In: O Globo, 2016. (http://oglobo.globo.com/sociedade/tecnologia/usuarios-deinternet-movel-no-brasil-crescem-7-nos-ultimos-seis-meses-chegam-383-milhoes-16195120)

QUINN, C. DESIGNING mLEARNING: Tapping into the Mobile Revolution for Organizational Performance. San Francisco: Pfeiffer, 2011.

SILVA, N. A. N. Abordagens Participativas para o Design: Metodologias e plataformas sociotécnicas como suporte ao design interdisciplinar e aberto a participação. 2012. $67 \mathrm{f}$. Dissertação (Mestrado) -PUC-SP, Curso de Pós-Graduação em Tecnologias da Inteligência e Design Digital.

TEIXEIRA, C.; LOPES, B. A digitalização de tudo no ensino superior em 2025. In: Radar do Futuro, 2017. (https://radardofuturo.com.br/ensino-a-distancia-em-2025/)

TEIXEIRA, O. A. F.; WESCHENFELDER, G. V. Evolução do EAD e as novas mídias. Revista Cesuca Virtual: Conhecimento sem Fronteiras, v. 1, n. 1, p. 1-21, 2013. 